Revista Eletrônica do Mestrado em Educação Ambiental

\title{
A Educação Ambiental no Brasil e na Espanha: reflexões alicerçadas na perspectiva crítica e transformadora
}

\author{
Ionara Cristina Albani ${ }^{1}$ \\ Universidade Federal do Rio Grande- FURG \\ https://orcid.org/0000-0003-3955-3326 \\ Cláudia da Silva Cousin ${ }^{2}$ \\ Universidade Federal do Rio Grande - FURG \\ https://orcid.org/0000-0002-8250-6800 \\ Macarena Esteban Ibañez ${ }^{3}$ \\ Universidade Pablo de Olavide - UPO \\ https://orcid.org/0000-0002-2246-4784
}

Resumo: Este artigo apresenta os caminhos trilhados pela Educação Ambiental tanto no Brasil quanto na Espanha, trazendo algumas reflexões sobre o tema. Discute elementos compreendidos como basilares para uma Educação Ambiental alicerçada na perspectiva crítica e transformadora (LOUREIRO, 2012). A partir deste diálogo e desta concepção, considera-se que os debates sobre Educação Ambiental, tanto no Brasil quanto na Espanha, têm surgido a partir da emergência de uma crise social, que vem se acentuando na sociedade e, consequentemente, preocupando e instigando parte da sociedade civil e os Movimentos Sociais que acreditam e lutam por um novo modelo de sociedade, fundamentado nos princípios da Educação Ambiental Crítica e Transformadora.

\footnotetext{
${ }^{1}$ Doutoranda em Educacão Ambiental. na Universidade Federal do Rio Grande - FURG. com doutorado sanduíche e cotutela realizados na Universidade Pablo de Olavide - UPO, na Espanha. Mestre em Educação Ambiental pela Universidade Federal do Rio Grande - FURG (2015). Pós Graduada-Latu Sensu em Desenvolvimento Regional pela Faculdade Meridional de Passo Fundo - IMED (2009). Licenciada em Pedagogia Anos Iniciais pela Universidade Estadual do Rio Grande do Sul - UERGS (2006). e-mail: ionara.albani@riogrande.ifrs.edu.br.

${ }^{2}$ Doutora e Mestre em Educacão Ambiental pela Universidade Federal do Rio Grande (FURG): Especialista em Desenvolvimento e Gerenciamento de Sistemas de Informação em Ciência e Tecnologia pela FURG (2001) e graduada em Geografia - Licenciatura Plena pela FURG (1995). Professora Associada e Pesquisadora do Instituto de Educação da FURG. Líder do Grupo de Pesquisa CIPEA - Ciranda Interdisciplinar de Pesquisa em Educação e Ambiente. Docente do Programa de Pós-graduação em Educação Ambiental - PPGEA e do curso de Licenciatura em Geografia. e-mail: profaclaudiacousin@ gmail.com.

Doutora na Universidade Pablo de Olavide-UPO, Departamento - Centro de Ciências Sociais da Faculdade de Educação e Psicologia Social. Formação Acadêmica: Licenciatura em Filosofia e Ciências da Educação (1996); Doutora em Pedagogia (2001). e-mail: mestib@upo.es.
}

Rev. Eletrônica Mestr. Educ. Ambient. Rio Grande, v. 36, n. 3, p. 212-234, set./dez. 2019.

E-ISSN 1517-1256 
Palavras-chave: Educação Ambiental Crítica e Transformadora. Brasil. Espanha.

\title{
La Educación Ambiental en Brasil y en España: reflexiones alicerzadas en la perspectiva crítica y transformadora
}

\begin{abstract}
Resumen: Este artículo presenta los caminos trillados por la Educación Ambiental tanto en Brasil como en España, trayendo algunas reflexiones sobre el tema. Discuta elementos comprendidos como basilares para una Educación Ambiental basada en la perspectiva crítica y transformadora (LOUREIRO, 2012). A partir de este diálogo y de esta concepción, se considera que los debates sobre Educación Ambiental, tanto en Brasil como en España, han surgido a partir de la emergencia de una crisis social, que viene acentuando en la sociedad y, consecuentemente, preocupando e instigando parte de la sociedad civil y los Movimientos Sociales que creen y luchan por un nuevo modelo de sociedad, basado en los principios de la Educación Ambiental Crítica y Transformadora. Palabras clave: Educación Ambiental Crítica y Transformadora. Brasil. España.
\end{abstract}

\section{The Environmental Education in Brazil and Spain: reflections based on the critical and transformative perspective}

\begin{abstract}
This article presents the paths traced by the Environmental Education in Brazil and Spain, bringing some thoughts on the topic. It discusses elements understood as basic for an Environmental Education based on the critical and transformative perspective (LOUREIRO, 2012). From this dialogue and this conception, we consider the debates on Environmental Education, both in Brazil and Spain, that arose from a social crisis, which has been intensifying in society and, consequently, worrying and instigating part of the civil society and Social Movements that believe and fight for a new model of society, based on the principles of Critical and Transformative Environmental Education.
\end{abstract}

Keywords: Critical and Transformative Environmental Education. Brazil. Spain.

\section{INTRODUÇÃO}

O descaso com a questão ambiental apresentado, principalmente, pelas grandes empresas e pelo Estado, caracterizado pelo querer abusivo do crescimento econômico, está neutralizando questões essenciais para a sustentabilidade, fazendo com que grupos preocupados com os problemas ambientais emergentes intensifiquem um diálogo a respeito da Educação Ambiental. Para além do descaso é latente o discurso de que "cada um deve fazer a sua parte", eximindo assim o sistema hegemônico da sua responsabilidade, que se materializa na desigualdade social e no uso desenfreado e irresponsável dos recursos naturais.

Fundamentadas nesta compreensão, são corriqueiras expressões como: "são as pequenas ações que fazem a diferença", "devemos começar por nós”, o importante é 
"plantar uma sementinha", etc. Expressões essas, usadas na ingenuidade por alguns, mas, na maioria das vezes, intencionalmente, induzem as pessoas a pensarem dessa forma e se sentirem culpadas por uma realidade em que são meros objetos de manipulação.

Desta forma, considera-se importante que a Educação Ambiental seja concebida como práxis, permeando todos os espaços formais e não formais da sociedade, considerando que os Movimentos Sociais e as Instituições de Ensino, tanto Básico como Superior, têm um papel essencial na consecução deste tema. Entende-se a Educação Ambiental como uma educação política, por constituir-se num contraponto a esta situação, consistindo em uma proposta emancipatória que busca a superação ou a negação de paradigmas existentes na sociedade globalizada, e a construção de uma outra globalização.

Instigadas por estes elementos que este artigo tem como objetivo trazer uma discussão sobre a Educação Ambiental no Brasil e na Espanha, convidando a refletir sobre aquela, alicerçada na perspectiva crítica e transformadora. Foi construído a partir de uma pesquisa de doutorado em desenvolvimento, no Programa de Pós-Graduação em Educação Ambiental - PPGEA, da Universidade Federal do Rio Grande - FURG, no Brasil, com parte da pesquisa sendo desenvolvida na Universidade Pablo de Olavide - UPO, na Espanha. A referida pesquisa tem como problema motivador: como a participação e o diálogo da FETRAF-SUL/CUT com a UERGS, que se materializou no convênio da turma de Pedagogia (2003-2007), potencializou a formação de educadores na perspectiva da Educação Ambiental Crítica e Transformadora?

O texto apresenta, inicialmente, os principais marcos institucionais, constituídos por espaços governamentais e documentos que pautaram/pautam o trabalho com a Educação Ambiental nos processos formativos, no Brasil, e a trajetória trilhada pela Educação Ambiental na Espanha, dando ênfase a alguns aspectos considerados primordiais para compreender o contexto discutido. Na sequência, desenvolve uma análise da temática nos dois países. Posteriormente, traz uma reflexão sobre a construção do campo da Educação Ambiental numa perspectiva crítica e transformadora, embasada, também, na pesquisa de doutorado, bem como a sua contribuição para a formação de educadores.

\section{Educação Ambiental no Brasil}

Os debates sobre Educação Ambiental, no Brasil, apesar de surgirem tardiamente, iniciaram bem antes de sua institucionalização por meio de Políticas Públicas. No final do século XIX e início do XX, podem-se citar alguns artigos, uma primeira legislação com Rev. Eletrônica Mestr. Educ. Ambient. Rio Grande, v. 36, n. 3, p. 212-234, set./dez. 2019. E-ISSN 1517-1256 
uma perspectiva conservacionista ${ }^{4}$, ações isoladas de organizações da sociedade civil, prefeituras municipais e governos estaduais em relação ao meio ambiente. Porém, o marco inicial da institucionalização da Educação Ambiental no Governo Federal foi a criação da Secretaria Especial do Meio Ambiente - SEMA, em 1973, vinculada ao Ministério do Interior. Conforme o Programa Nacional de Educação Ambiental - ProNEA:

A SEMA estabeleceu, como parte de suas atribuições, "o esclarecimento e a educação do povo brasileiro para o uso adequado dos recursos naturais, tendo em vista a conservação do meio ambiente", e foi responsável pela capacitação de recursos humanos e sensibilização inicial da sociedade para as questões ambientais (BRASIL, 2005).

Essa Secretaria protagonizou algumas ações relacionadas a projetos de Educação Ambiental, direcionados à inserção desta temática nos currículos escolares do $1^{\circ}$ e $2^{\circ}$ graus, na região Norte. Também, realizou seis cursos de especialização em Educação Ambiental e cinco seminários sobre Universidade e Meio Ambiente, além de produzir, divulgar e publicar materiais sobre o tema ambiental.

Outros avanços importantes na institucionalização da Educação Ambiental, anteriores à Constituição Federal de 1988, foram a inclusão da mesma em todos os níveis de ensino, o que foi estabelecido em 1981, no âmbito legislativo, pelo Programa das Nações Unidas pelo Meio Ambiental - PNUMA e, em 1987, a definição de que a Educação Ambiental deveria ter caráter interdisciplinar, oficializando a posição do governo, por meio do Conselho Federal de Educação, através do Parecer 226. Loureiro faz uma avaliação dos debates e ações sobre Educação Ambiental, no Brasil, até este período, enfatizando que:

Num breve olhar para o passado, constatamos que o debate ambiental se instaurou no país sobre a égide do regime militar nos anos 70 , muito mais por forças de pressões internacionais do que por movimentos sociais de cunho ambiental, nacionalmente consolidados. Até a promulgação da Constituição Federal de 1988, a política ambiental brasileira foi gerida de forma centralizada, sem a participação popular efetiva na definição de suas diretrizes e estratégias [...] O movimento ambientalista ganha caráter público e social efetivo no Brasil apenas no início da década de 80, com raras exceções anteriores em estados como o Rio Grande do Sul (LOUREIRO, 2012, p. 88, grifo do autor).

\footnotetext{
${ }^{4}$ A perspectiva conservacionista agrupa as proposições centradas na conservação dos recursos, tanto no que concerne à sua qualidade como à sua quantidade: a água, o solo, a energia, as plantas (principalmente as plantas comestíveis e medicinais) e os animais (pelos recursos que podem ser obtidos deles), o patrimônio genético, o patrimônio construído (SAUVÉ, 2005).
}

Rev. Eletrônica Mestr. Educ. Ambient. Rio Grande, v. 36, n. 3, p. 212-234, set./dez. 2019.

E-ISSN 1517-1256 
Dando seguimento a esta trajetória nacional, em 1988, a partir da Constituição Federal, Capítulo VI - Do Meio Ambiente, Artigo 225, Inciso VI, incumbe ao Poder Público: "Promover a educação ambiental em todos os níveis de ensino e a conscientização pública para a preservação do meio ambiente" (BRASIL, 1988). É importante ressaltar que a Constituição Federal não faz menção aos Movimentos Sociais neste capítulo relacionado ao Meio Ambiente.

Em 1991, foi criado o Grupo de Trabalho de Educação Ambiental do Ministério da Educação - MEC, o qual, em 1993, transformou-se na Coordenação Geral de Educação Ambiental - COEA/MEC. Ainda nesse ano, foi criada a Divisão de Educação Ambiental, do Instituto Brasileiro de Meio Ambiente e dos Recursos Naturais Renováveis - IBAMA, órgão instituído em 1989, com a função de ser o grande executor da política ambiental e de gerir de forma integrada essa área no país.

Em 1992, foi criado o Ministério do Meio Ambiente - MMA, com o objetivo de promover a preservação ambiental no Brasil, aumentando o conhecimento e fiscalizando a execução de políticas relacionadas ao tema. Além disso, o órgão tinha como proposta defender a sustentabilidade no uso de recursos naturais e luta para que o planejamento público respeitasse os preceitos do desenvolvimento sustentável.

Em 1994, em virtude da Constituição Federal de 1988 e dos compromissos assumidos na Rio 92, o MMA juntamente com o MEC criou o Programa Nacional de Educação Ambiental - ProNEA. O referido programa, sintonizado com o Tratado de Educação Ambiental para Sociedades Sustentáveis e Responsabilidade Global, apresenta as diretrizes, os princípios, a missão, os objetivos e as linhas de ação em relação à Educação Ambiental, além do histórico do processo de institucionalização desta no Brasil. Para explicar a proposta, o Programa Nacional de Educação Ambiental enfatiza que:

O ProNEA propõe um constante exercício de transversalidade para internalizar, por meio de espaços de interlocução bilateral e múltipla, a Educação Ambiental no conjunto do governo, nas entidades privadas e no terceiro setor; enfim, na sociedade como um todo. Estimula o diálogo interdisciplinar entre as políticas setoriais e a participação qualificada nas decisões sobre investimentos, monitoramento e avaliação do impacto de tais políticas (BRASIL, 2005).

Cabe enfatizar que, neste documento, os Movimentos Sociais somente são mencionados na justificativa, quando fala sobre o quadro de exclusão social e elevado nível de pobreza da população. Traz, com um desafio, diminuir o distanciamento entre a letra das leis e sua efetiva aplicação, sobretudo no que se refere às dificuldades encontradas Rev. Eletrônica Mestr. Educ. Ambient. Rio Grande, v. 36, n. 3, p. 212-234, set./dez. 2019. E-ISSN 1517-1256 
por políticas institucionais e Movimentos Sociais voltados à consolidação da cidadania entre segmentos sociais excluídos (BRASIL, 2005).

Em 1997, produzidos com base na Lei de Diretrizes e Bases da Educação Nacional - LDBEN, foram aprovados, pelo Conselho Nacional de Educação, os Parâmetros Curriculares Nacionais - PCN, nos quais as diretrizes são voltadas, sobretudo, para a estruturação e reestruturação dos currículos escolares, obrigatórias para a rede pública e opcionais para as instituições privadas. Conforme Campos (2015, p. 275): “O objetivo desse documento foi oferecer orientações e apoio para que os professores pudessem readaptar o currículo escolar, incluindo os temas transversais na construção de projetos pedagógicos autônomos." Os PCNs tiveram o papel, também, de subsidiar as escolas na elaboração dos seus projetos educativos, estabelecendo pilares fundamentais para guiar a Educação Formal e a própria relação escola-sociedade no cotidiano. Sobre os PCNs, Loureiro ressalta que:

Apesar das críticas que recebeu pelo modo como pensou a transversalidade em educação (mantendo como eixos principais as disciplinas de conteúdos formais-português, matemática, ciências, história e geografia) e pela baixa operacionalização da proposta, teve o mérito de inserir a temática ambiental não como disciplina e de abordá-la articulada às diversas áreas de conhecimento (LOUREIRO, 2012, p. 92).

Em 1999 foi aprovada a Lei $n^{\circ}$ 9.795/99, que dispõe sobre a Política Nacional de Educação Ambiental - PNEA, ressaltando, em seu art. $1^{\circ}$, que a Educação Ambiental é um componente essencial e permanente da educação nacional, tendo que, de forma articulada, estar presente em todos os níveis e modalidades do processo educativo formal e não formal. Este documento traz como uma de suas diretrizes para o Sistema de Ensino: "Estabelecer um fluxo de capilarização com instituições de educação e meio ambiente dos estados e municípios, ONGs e movimentos sociais como forma de chegar à totalidade das escolas" (BRASIL, 1999).

Em 2003, foi instituída a Comissão Intersetorial de Educação Ambiental - CISEA, no Ministério do Meio Ambiente, com a ideia de ampliar o alcance da Educação Ambiental e trabalhar esta a partir do conceito de transversalidade, como está previsto na PNEA.

Em 2012, a Direção Geral de Educação Ambiental do MEC propôs as Diretrizes Curriculares Nacionais para Educação Ambiental - DCNEA, como resposta à demanda por uma Educação Ambiental Crítica e Transformadora, que assuma seu papel transversal 
(CRUZ; BIGLIARDI, 2012). As DCNEAs orientam a implementação da PNEA e consideram a Educação Ambiental como atividade intencional da prática social, que deve atribuir ao desenvolvimento individual um caráter social. Porém, este documento também não faz menção alguma aos Movimentos Sociais na discussão da Educação Ambiental.

No ano de 2017 foi publicada a Resolução $\mathrm{CNE} / \mathrm{CP} \mathrm{n}^{\circ}$ 2, que institui e orienta a implementação da Base Nacional Comum Curricular - BNCC, a ser respeitada obrigatoriamente durante as etapas e as respectivas modalidades de ensino, no âmbito da Educação Básica. Neste documento, a Educação Ambiental é mencionada apenas uma vez, na introdução, sendo considerada mais um dos temas que deve ser incorporado nos currículos e nas propostas pedagógicas das escolas de forma transversal (BEHREND; COUSIN; GALIAZZI, 2018).

A partir dessas políticas e ações, não se pode negar que houve avanços no que tange à institucionalização da política de Educação Ambiental no Brasil, porém esses avanços não são suficientes, ao se pensar na democratização dessa política e, mais que isso, como uma possibilidade de resistência e transformação da sociedade. Loureiro considera que a Educação Ambiental ainda não se efetivou como uma Política Pública de caráter democrático:

[...] a Educação Ambiental insere-se no bojo destas políticas e continua a ganhar espaço no cenário nacional, dado o seu papel estratégico de preparação das atuais e futuras gerações para o enfrentamento das questões socioambientais. Logo, questionamos como a Educação Ambiental dialoga com a função avaliação no ciclo de políticas públicas? Se, por um lado, é crescente e decisiva a contribuição da Educação Ambiental para a solução/minimização dos desafios socioambientais planetários, por outro, mostra-se imperativa a necessidade de julgar os efeitos das políticas, programas e projetos implantados. De que tipo de Educação Ambiental precisamos? Quais são os objetivos e resultados a serem realmente perseguidos? (LOUREIRO, 2012, p. 115).

Infelizmente, a Educação Ambiental ganhava espaço no cenário nacional, mas atualmente outro cenário está se desenhando. Atualmente, a questão ambiental no Brasil enfrenta retrocessos sem precedentes. Isso se evidencia por meio da extinção dos setores de Educação Ambiental dos Ministérios da Educação e Meio Ambiente, que constituíam o órgão gestor da PNEA, além de ações como a extinção das Secretarias de Mudanças no Clima, da Articulação Institucional e da Cidadania Ambiental, a transferência da Agência Nacional das Águas, da Secretaria Nacional de Segurança Hídrica e do Conselho Nacional de Recursos Hídricos, o enfraquecimento e perda de autonomia do IBAMA e do Instituto 
Chico Mendes da Conservação da Biodiversidade - ICMBio, o enfraquecimento de políticas indigenistas, a liberação acelerada de agrotóxicos, o esvaziamento de políticas de Segurança Alimentar, o desmonte do CONAMA, e outros órgãos colegiados. Apresenta-se um descaso, por parte do Estado, que desconsidera anos de luta, trabalho e conquista referente a este tema. E na Espanha? Como se constituiu e está se constituindo este processo?

\section{Educação Ambiental na Espanha}

Para dar início à discussão sobre Educação Ambiental na Espanha, assim como no Brasil, buscou-se as primeiras iniciativas e/ou discussões tecidas naquele contexto. Nesse sentido, Benayas, Gutiérrez e Hernandéz (2003, p. 35) salientam que: "En España, al igual que en otros muchos países, las primeras iniciativas en torno a la EA comenzaron a finales de los años 70 promovidas principalmente por grupos de educadores y colectivos ambientalistas."

Assim, a primeira reunião específica de Educação Ambiental, que aconteceu na Espanha, foi realizada na cidade de Sevilha, em outubro de 1979. Nesta reunião, tiveram conferências sobre a questão ambiental na formação de educadores. Este seminário, no qual participou um número reduzido de profissionais, principalmente da Universidade, surgiu como uma resposta nacional ao Congresso Intergovernamental de Tbilisi, realizado na Rússia (atual Geórgia), em 1977. Conforme Benayas, Gutiérrez e Hernandéz:

Este evento, que no tuvo ninguna repercusión social de relevancia, se limitó a hacerse eco de los principios de la EA enunciados en la reunión internacional, y manifestar los numerosos obstáculos y dificultades a que se enfrentaba su aplicación en los distintos ámbitos educativos y ambientales del país (BENAYAS; GUTIÉRREZ; HERNANDÉZ, 2003, p. 39).

Mayer (1998) enfatiza que nos anos oitenta, nascem e se desenvolvem, propostas de Educação Ambiental, reconhecendo que os comportamentos são guiados muito mais pelas emoções e pelos valores que pelo conhecimento e, portanto, é necessário não apenas oferecer informações, mas também propor experiências que reconstruam a conexão entre homem e o meio ambiente. Assim, em 1984, em Barcelona, aconteceu a I Jornada Galega de Educação Ambiental, alicerçada na perspectiva conservacionista, sendo constituída, também, por atividades pontuais, nas escolas. Foi a primeira ocasião em que se reuniram 
muitas pessoas que estavam trabalhando com a temática, porém, na sua maioria, com um perfil técnico. A partir disto, muitas foram as convocatórias de jornadas, reuniões e encontros especializados, em quase todas as Comunidades Autônomas Espanholas (BENAYAS; GUTIÉRREZ; HERNANDÉZ, 2003).

Em 1987 foi realizada, em Valsaín, a II Jornada Nacional de Educação Ambiental. Esta reunião serviu para verificar o grande dinamismo que a Educação Ambiental tinha experimentado na Espanha e, especialmente, para iniciar uma fase de maior maturidade. A partir desta reunião, e patrocinados pela Direção Geral de Meio Ambiente do Ministério de Obras Públicas e Urbanismo - MOPU foi realizado uma série de seminários permanentes que, por volta de cinco anos, trabalharam no aprofundamento de tópicos específicos. Os materiais produzidos por esses seminários se tornaram um importante ponto de referência conceitual. Estes estudos serviram de base de discussão para a III Jornada Nacional de Educação Ambiental, que foi realizada em dezembro de 1998, em Pamplona (BENAYAS; GUTIÉRREZ; HERNANDÉZ, 2003).

No âmbito mais acadêmico, quatro congressos foram realizados com a tentativa de uma projeção internacional. Os dois primeiros organizados pelo Instituto Universitário de Ciências Ambientais da Universidade Complutense, em Madrid, nos anos de 1988 e 1995, enquanto que os outros dois foram promovidos pela Universidade de Santiago de Compostela, em 1996, e pela Universidade de Salamanca, em 1997 (BENAYAS; GUTIÉRREZ; HERNANDÉZ, 2003). Sobre a discussão e o trabalho com a Educação Ambiental estarem mais atrelados ao meio acadêmico, Esteban Ibañez (2017, p. 225-226) problematiza: “[...] el principal reto de la EA en España sigue siendo a día de hoy, transpasar los limites de la escuela o lo instituto y alcanzar, de modo efectivo al resto de colectivos sociales [...]".

Em 1990, a Espanha lançou a Lei Orgânica de Ordenação Geral do Sistema Educativo - LOGSE, seguindo as recomendações da UNESCO - PNUMA, e adotando diretrizes para evitar que a Educação Ambiental não fosse trabalhada como uma disciplina, mas sim como um tema transversal do currículo (DUARTE, 2018). Esteban Ibañez (2017, p. 228) salienta: "La LOGSE establece que la EA debe ser uno de los principios educativos básicos que deben orientar toda la actividad educativa." Sobre isso Benayas, Gutiérrez e Hernadéz (2003, p. 21) enfatizam que, atualmente, os programas nos diferentes níveis educativos, incluem o trabalho com temas ambientais, e explicam: "En España, aunque con un cierto retraso, la EA se incorporó como materia transversal de los nuevos diseños curriculares elaborados a partir de la implantación de la reforma del sistema educativo." Rev. Eletrônica Mestr. Educ. Ambient. Rio Grande, v. 36, n. 3, p. 212-234, set./dez. 2019. E-ISSN $1517-1256$ 
Mayer comenta que o fato de a Educação Ambiental ser aludida, nos documentos, a partir da transversalidade, contribuiu para o trabalho dos educadores:

En todos los documentos internacionales, y también para la Unión Europea, la educación ambiental no se considera como una disciplina escolar autónoma sino como una enseñanza lo más interdisciplinar y transversal posible (Giolitto et al., 1997). Sin embargo, en los últimos diez años, educadores de todas las disciplinas, aunque en mayor medida enseñantes de disciplinas científicas, han decidido dedicar al medio ambiente y a la educación ambiental una parte de su labor didáctica (MAYER, 1998, p. 217).

Seguindo com a trajetória da Educação Ambiental na Espanha, em 1995 foi criado pelo governo, o chamado "Organismo Autônomo Parques Nacionais" para tratar dos impactos ambientais. Esse órgão estava atrelado ao Ministério da Agricultura. Em 1996, finalmente, foi instituído o Ministério do Meio Ambiente.

Em seguida, ainda nos anos noventa, na Comunidade Autônoma de Galícia, como parte da Estratégia Galega de Educação Ambiental - EGEA, aprovada pelo Conselho Galego de Meio Ambiente, em 1999, surgem as primeiras experiências de Educação Ambiental, atreladas à escola, que eram conhecidas como escola de auditorias ambientais ou eco-auditorias. Sua finalidade era a inclusão da Educação Ambiental no currículo, baseando-se em estratégias metodológicas que pudesses satisfazer os critérios ambientais. Porém, por diversos motivos como, questões de planejamento, ausência de formação para e com os educadores, dificuldade de trabalho em grupo e de forma interdisciplinar, essas iniciativas não conseguiram se consolidar. Assim, a proposta das eco-auditorias foram transformadas no Programa "Agenda 21 Escolar" (SALORT, 2016). É importante ressaltar que a EGEA foi pensada para o período de 2000-2006, porém não atingiu a sociedade de uma forma efetiva. Cartea e Santiago problematizam essa questão, por meio de uma pesquisa realizada:

[...] más del 50\% de los ayuntamientos estudiados desconocían la EGEA, el documento que debería orientar en buena parte sus iniciativas educativo ambientales; mientras que otros sectores como empresas de Educación Ambiental o colectivos ecologistas, con porcentajes de conocimiento mayores $(77,1 \%$ y $78,3 \%$, respectivamente), no dejan de tener cifras relativamente bajas para actores que por su papel en la promoción de la Educación Ambiental, tendrían que conocerla en un mayor porcentaje (CARTEA; SANTIAGO, 2010, p. 3).

Porém, a discussão sobre e o trabalho com a Educação Ambiental na Espanha, começa a ganhar maior ênfase, em 1999, a partir da publicação do Livro Branco da Rev. Eletrônica Mestr. Educ. Ambient. Rio Grande, v. 36, n. 3, p. 212-234, set./dez. 2019. E-ISSN $1517-1256$ 
Educação Ambiental, que se constituiu como uma estratégia nacional, por meio de uma ampla participação pública, impulsionada por um acordo entre os Governos Nacionais e as Comunidades Autônomas. Este documento é resultante de um estudo lançado pelo Ministério do Meio Ambiente, incluindo tanto os objetivos e princípios básicos que orientam a Educação Ambiental, como os instrumentos disponíveis para este trabalho. $\mathrm{O}$ documento é produto de um trabalho coletivo, para o qual foram convidadas tanto as administrações públicas, como as associações, além de representantes de diferentes setores sociais, e profissionais de Educação Ambiental. Esteban Ibañez comenta que o Livro Branco potencializou a discussão e o trabalho com a Educação Ambiental, tanto na atuação administrativa como no sistema educativo:

Está claro que el Libro Blanco surge como prescripción de que debe ser y atender la EA en España, y recopila las perspectivas de sindicatos, empresas, profesionales y expertos en la materia, que hacen del mismo un documento participativo y reflexivo para su uso y puesta en marcha de programas de EA (ESTEBAN IBAÑEZ, 2017, p. 226-227).

Pela primeira vez na Espanha, foi construído um documento com a proposição de analisar e reunir informações da reflexão e da experiência de mais de 20 anos de trabalho em diferentes áreas. O Livro Branco propôs uma série de recomendações e ações para orientar a Educação Ambiental, distribuídas em cinco marcos de ação: a comunidade, a administração geral e regional, o sistema educacional, empresas e sindicatos, e a mídia. Este processo foi realizado, abordando as recomendações do Capítulo 36 da Agenda 21 (FERNANDÉZ; ORTEGA, 2006).

Posteriormente a isso, em abril de 2004, foi realizada uma reunião do Seminário Técnico sobre Estratégias de Educação Ambiental, em Barcelona, que teve como objetivo, analisar as iniciativas que estavam acontecendo nas diferentes Comunidades Autônomas, sendo que foi detectada a necessidade de refletir sobre a evolução da Educação Ambiental, a partir da publicação do Livro Branco sobre Educação Ambiental na Espanha, em 1999 (FERNÁNDEZ; ORTEGA, 2016).

Outro marco na Educação Ambiental Galega foi a criação da Sociedade Galega de Educação Ambiental - SGEA, em maio de 2001. Não passou mais de duas décadas desde as primeiras iniciativas identificadas neste campo educacional, para possibilitar a constituição de um coletivo com disposição para articular um projeto, envolvendo agentes, indivíduos e grupos que trabalham na e a partir da Galícia, para a implementação de respostas educacionais à crise ambiental. Entre as finalidades definidas naquela época, a 
SGEA optou por promover uma "Educação Ambiental de Qualidade que permitisse responder às necessidades de uma sociedade mais justa e responsável pelo meio ambiente", para promover "a pesquisa multidisciplinar em Educação Ambiental" e divulgar seus resultados e conclusões, além da "criação de fóruns para facilitar a troca de experiências e formação em Educação Ambiental" com outros parceiros sociais e institucionais (CARTEA; SANTIAGO, 2010). Sobre a constituição do SGEA, Cartea e Santiago explicam que se originou na década das estratégias da Educação Ambiental, etapa que teve como marco inicial, a publicação do Livro Branco:

La SGEA, como buena parte del movimiento asociativo emergente de la Educación Ambiental en toda España, apareció en sintonía con la que puede caracterizarse como década de las estrategias de Educación Ambiental. El hito que marca el inicio de esta etapa es la publicación en 1999 del Libro Blanco de la Educación Ambiental en España, impulsado por el Ministerio de Medio Ambiente del primer gobierno de José M. Aznar, que servirá de inspiración e impulso institucional para que el mosaico autonómico se vaya poblando de documentos estratégicos que intentan, a partir de un diagnóstico del estado de la Educación Ambiental en cada comunidad, establecer objetivos, principios y retos para su desarrollo a medio y largo plazo (CARTEA; SANTIAGO, 2010, p. 2).

Por meio do SGEA, foi concretizado o Projeto Fênix que, durante quatro anos, serviu de plataforma para o desenvolvimento de uma pesquisa-ação no âmbito da Educação Ambiental Galega. Este projeto surgiu com o encerramento da EGEA, para dar conta de uma demanda que havia ficado descoberta pelas dificuldades apresentadas durante a execução daquela, e que, conforme avaliam Cartea e Santiago, esse processo (2010, p. 3): "[...] fue una oportunidad en gran medida desaprovechada para potenciar la Educación Ambiental como instrumento poderoso delante de los desafíos de la crisis ambiental y sus manifestaciones em Galicia."

Assim, a SGEA propôs ao responsável pelo Ministério do Meio Ambiente, a possibilidade de retomar o processo aberto com o EGEA, para dar um novo impulso. A ideia principal do Projeto Fênix, não foi tanto para elaborar um novo documento estratégico - um novo produto semelhante ao que já existia -, mas, para partir dele, gerar um processo diagnóstico do campo da Educação Ambiental, por meio de uma metodologia que permitiria combinar e estender ao longo do tempo, diferentes ações com dupla intenção: diagnosticar e dinamizar o setor (CARTEA; SANTIAGO, 2010). O projeto foi desenvolvido em dois períodos, sendo o primeiro de fevereiro de 2006 a novembro de

Rev. Eletrônica Mestr. Educ. Ambient. Rio Grande, v. 36, n. 3, p. 212-234, set./dez. 2019. 
2007, e o segundo de janeiro de 2008 a dezembro de 2009. Cartea e Santiago comentam sobre os quatro anos de trabalho:

El tiempo dirá si el trabajo realizado ha tenido la repercusión y el impacto deseable. No obstante, consideramos que se pusieron en marcha mecanismos y resortes que, con un poco más de tiempo y trabajo, pueden contribuir a la consolidación y la promoción de la Educación Ambiental en nuestra comunidad (CARTEA; SANTIAGO, 2010, p. 10).

Cartea e Santiago (2010) enfatizam, ainda, que a SGEA vem atingindo cada vez mais força ao conseguir aglutinar um número crescente $\mathrm{e}$, cada vez mais representante, de atores e agentes da Educação Ambiental. Atualmente é uma das organizações no campo da Educação Ambiental com maior vitalidade do Estado, como referenciado pelo Centro Nacional de Educação Ambiental, pela sua participação ativa na criação da Federação de Entidades de Educação Ambiental, no ano 2008 - um projeto promovido em conjunto com entidades similares de outras comunidades.

Outra questão que merece destaque nos caminhos percorridos pela Educação Ambiental na Espanha, é que no ano de 2006, a LOGSE deu lugar a uma nova lei, Lei Orgânica de Educação - LOE, a qual suprimiu o termo "Educação Ambiental" da sua redação, por entender que esta já permeava todo o processo educativo, de forma transversal. Porém, a incorporação da Educação Ambiental no currículo ainda permanece sendo um desafio. Esteban Ibañez problematiza a LOE e menciona a Lei Orgânica para a Melhoria da Qualidade Educativa - LOMCE, que foi promulgada em 2013 e está em vigor atualmente:

Hablamos que uno de los aspectos más relevantes es la inclusión de la asignatura Educación para la Ciudadanía, que resultó ser polémica y arbitraria. En la actualidad está en vigor la LOMCE, que no exenta de polémica en su entrada en vigor, es la marcará el devenir del tratamiento de la EA de ahora en adelante. Si bien, hemos hablado de la EA con la LOGSE, tratada como "eje transversal" y delegada en ocasiones a la voluntad de desarrollo del profesorado, con la LOMCE vislumbramos, con el paso de etapas escolares un mayor hincapié en el tratamiento de la EA (ESTEBAN IBAÑEZ, 2017, p. 229).

Outra referência da Educação Ambiental na Espanha é o programa de pósgraduação, que hoje é chamado de Mestrado Interuniversitário de Educação Ambiental. Este programa teve início no ano de 2008 e era conhecido como Mestrado de Educador(a) Ambiental. O programa, com o nome de "Mestrado Interuniversitário de Educação

Rev. Eletrônica Mestr. Educ. Ambient. Rio Grande, v. 36, n. 3, p. 212-234, set./dez. 2019. 
Ambiental", iniciou em novembro de 2018. É a primeira edição oficial com estas características, adaptado ao Espaço Europeu do Ensino Superior. Inicialmente, está sob a coordenação da Universidade de Cádiz - UCA, sendo que contribuem na organização, também, a Universidade de Almería - UAL, a Universidade de Córdoba - UCO, a Universidade de Granada - UGR, a Universidade de Huelva - UHU, a Universidade de Málaga - UMA, e a Universidade Pablo de Olavide - UPO. O programa é constituído por professores de todas as Universidades andaluzas e de várias Instituições Espanholas. A $7^{\mathrm{a}}$ edição do mesmo foi desenvolvida em 2015-2016, sendo que, nos últimos anos, mais de 250 alunos foram capacitados como educadores ambientais com Mestrado (UNIVERSIDADE PABLO DE OLAVIDE, 2019).

Desta forma, percebe-se que os debates sobre Educação Ambiental, tanto no Brasil quanto na Espanha, têm surgido a partir da emergência de uma crise social, que vem se acentuando na sociedade e, consequentemente, preocupando e instigando parte da sociedade civil e os Movimentos Sociais que acreditam e lutam por um novo modelo de sociedade, fundamentado nos princípios da educação Ambiental Crítica e Transformadora. Para exemplificar, a seguir, serão tecidas reflexões dialógicas, a partir das trajetórias e dos fundamentos da Educação Ambiental no Brasil e na Espanha.

\section{REFLEXÕES DIALÓGICAS SOBRE A EDUCAÇÃO AMBIENTAL NO BRASIL E NA ESPANHA}

A partir da escrita e discussão da trajetória da Educação Ambiental, verificou-se que, tanto no Brasil quanto na Espanha, os debates sobre esta temática tiveram início nos anos 70. Compreende-se que, no Brasil, a Educação Ambiental é trabalhada como um potencial para viabilizar a sustentabilidade, com a finalidade de "[...] criar novos modos de vida, baseados em atender às necessidades básicas de todos, sem distinções étnicas, físicas, de gênero, idade, religião ou classe” (BRASIL, 2005). Já na Espanha, a temática tem o intento de visar à aquisição de conhecimentos, habilidades, atitudes e valores, além da integração nos Planos Escolares.

Tanto no Brasil, quanto na Espanha, a nível nacional, a Educação Ambiental é representada pelo Ministério da Educação (na Espanha, chamado de Ministério de Educação e Cultura) e pelo Ministério do Meio Ambiente. Em relação à legislação vigente, no Brasil, a Constituição Federal prevê a inclusão da Educação Ambiental em todos os níveis de ensino, sendo que a LDBEN a considera como um tema transversal e os PCNs Rev. Eletrônica Mestr. Educ. Ambient. Rio Grande, v. 36, n. 3, p. 212-234, set./dez. 2019. E-ISSN 1517-1256 
têm como objetivo, orientar e apoiar os educadores na readaptação do currículo escolar no que diz respeito a transversalidade. Como resposta a uma demanda mais específica, encontram-se as DCNEAS que orientam a implementação da PNEA e consideram a Educação Ambiental como atividade intencional da prática social, alicerçada na perspectiva crítica e transformadora. Já a BNCC menciona a Educação Ambiental apenas na Introdução do documento, considerando que esta deve ser trabalhada de forma transversal, assim como outras temáticas. $\mathrm{Na}$ Espanha, inicialmente, a temática era regida pela LOGSE, que compreendia a Educação Ambiental como tema transversal, sendo substituída pela LOE, que retirou o termo "Educação Ambiental" de sua redação, por entender que esta já permeava todo o processo educativo, de forma transversal. Atualmente é orientada pela LOMCE, que externa uma maior ênfase no tratamento da Educação Ambiental.

Os marcos governamentais que resultaram em espaços representativos no Estado, bem como em documentos ou leis referentes à Educação Ambiental, foram significativos nesses anos de debate e luta sobre a importância desta temática para a sociedade, tanto no Brasil, quanto na Espanha. Nos dois países, a concepção de Educação Ambiental abordada nos documentos está alicerçada na transversalidade e na interdisciplinaridade, sendo que no Brasil se evidencia a questão da totalidade, enquanto que na Espanha se observa a discussão sobre a preservação do meio ambiente.

Apesar da conquista de diversos espaços, da formulação de documentos e da instituição de leis relacionados à Educação Ambiental, muitos ainda são os desafios para que de fato esse trabalho se consolide. No Brasil, um dos principais desafios é o fortalecimento da luta e a priorização da Educação Ambiental como pauta dos Movimentos Sociais, pois se avalia que as possibilidades de trabalhar este tema juntamente com o Estado, estão sendo extintas, a exemplo das reestruturações apresentadas atualmente, as quais extinguiram os setores de Educação Ambiental dos Ministérios da Educação e Meio Ambiente, que constituíam o órgão gestor da PNEA. Na Espanha, avalia-se que um dos desafios é participação e o diálogo dos Movimentos Sociais com as Instituições de Ensino Superior, como uma das possibilidades para potencializar o processo de construção para colocar em prática o trabalho com a Educação Ambiental, conforme dispõem os documentos. O quadro 1 exemplifica as discussões sobre a Educação Ambiental no Brasil e na Espanha.

Rev. Eletrônica Mestr. Educ. Ambient. Rio Grande, v. 36, n. 3, p. 212-234, set./dez. 2019. 
Quadro 1: Educação Ambiental no Brasil e na Espanha

\begin{tabular}{|c|c|c|}
\hline \multicolumn{3}{|c|}{ EDUCAÇÃO AMBIENTAL } \\
\hline PAÍSES & BRASIL & ESPANHA \\
\hline Início da discussão & $\begin{array}{l}\text { Final do século XIX }- \\
\text { início do XX. }\end{array}$ & Final dos anos 70. \\
\hline Finalidades & $\begin{array}{l}\text { Viabilização da } \\
\text { sustentabilidade; } \\
\text { Criar novos modos de vida, } \\
\text { baseados em atender às } \\
\text { necessidades básicas de } \\
\text { todos, sem distinções } \\
\text { étnicas, físicas, de gênero, } \\
\text { idade, religião ou classe. }\end{array}$ & $\begin{array}{l}\text { Aquisição } \\
\text { conhecimentos, } \\
\text { habilidades, atitudes e } \\
\text { valores; } \\
\text { Integração nos Planos } \\
\text { Escolares. }\end{array}$ \\
\hline Lei vigente & $\begin{array}{l}\text { Constituição Federal de } \\
\text { 1998-CF; } \\
\text { Lei de Diretrizes e Bases } \\
\text { da Educação Nacional - } \\
\text { LDBEN; } \\
\text { Parâmetros Curriculares } \\
\text { Nacionais - PCNs. } \\
\text { Diretrizes Curriculares } \\
\text { Nacionais para Educação } \\
\text { Ambiental - DCNEAs. }\end{array}$ & $\begin{array}{l}\text { Lei Orgânica para a } \\
\text { Melhoria da Qualidade } \\
\text { Educativa }\end{array}$ \\
\hline $\begin{array}{ll}\text { Instituições do Estado } \\
\text { que representam a } \\
\text { Educação Ambiental a } \\
\text { nível nacional }\end{array}$ & $\begin{array}{l}\text { Ministério do Meio } \\
\text { Ambiente - MMA; } \\
\text { Ministério da Educação - } \\
\text { MEC. }\end{array}$ & $\begin{array}{lll}\text { Ministério } & \text { de } & \text { Educação e } \\
\text { Cultura; } & & \\
\text { Ministério } & \text { de } \\
\text { Ambiente. } & & \\
\end{array}$ \\
\hline Principais marcos & $\begin{array}{lrr}\text { Criação da } & \text { Secretaria } \\
\text { Especial do } & \text { Meio } \\
\text { Ambiente } & \text { SEMA (1973); } \\
\text { Criação do Ministério do } \\
\text { Meio Ambiente } & \text { (1992); } \\
\text { Criação do } & \text { Programa } \\
\text { Nacional de } & \text { Educação } \\
\text { Ambiental } & \text { ProNEA } \\
\text { (1993); } & \\
\text { Aprovação do Programa de } \\
\text { Pós-Graduação } \\
\text { Educação Ambiental } \\
\text { PPGEA, da Universidade } \\
\text { Federal do Rio Grande - } \\
\text { FURG / Único programa }\end{array}$ & 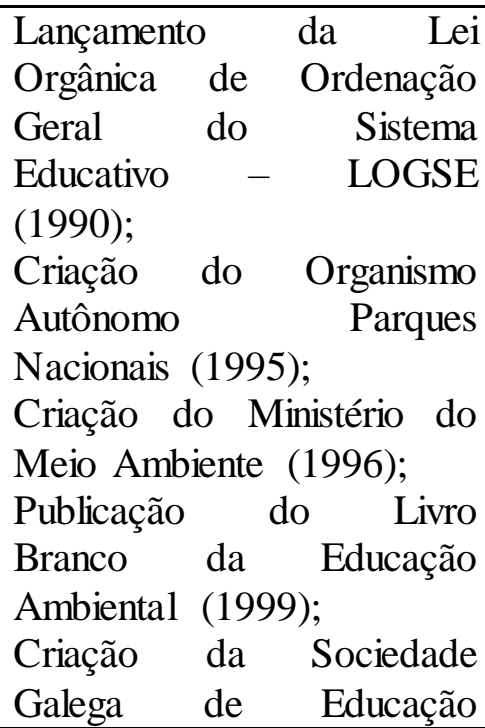 \\
\hline
\end{tabular}

Rev. Eletrônica Mestr. Educ. Ambient. Rio Grande, v. 36, n. 3, p. 212-234, set./dez. 2019. 


\begin{tabular}{|c|c|c|}
\hline & 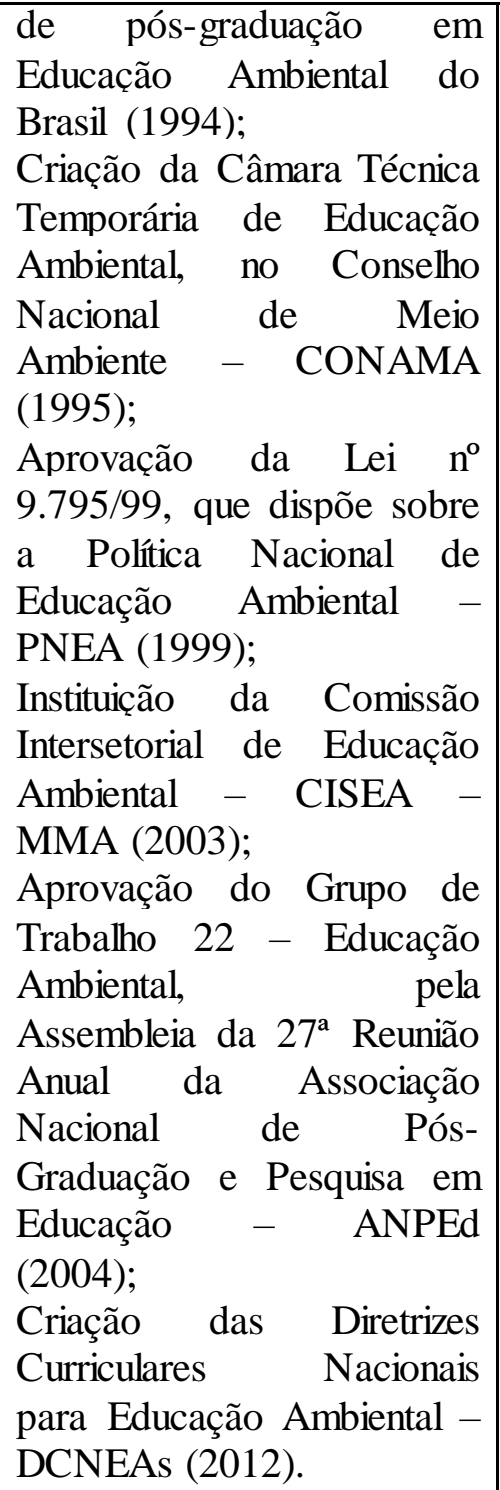 & 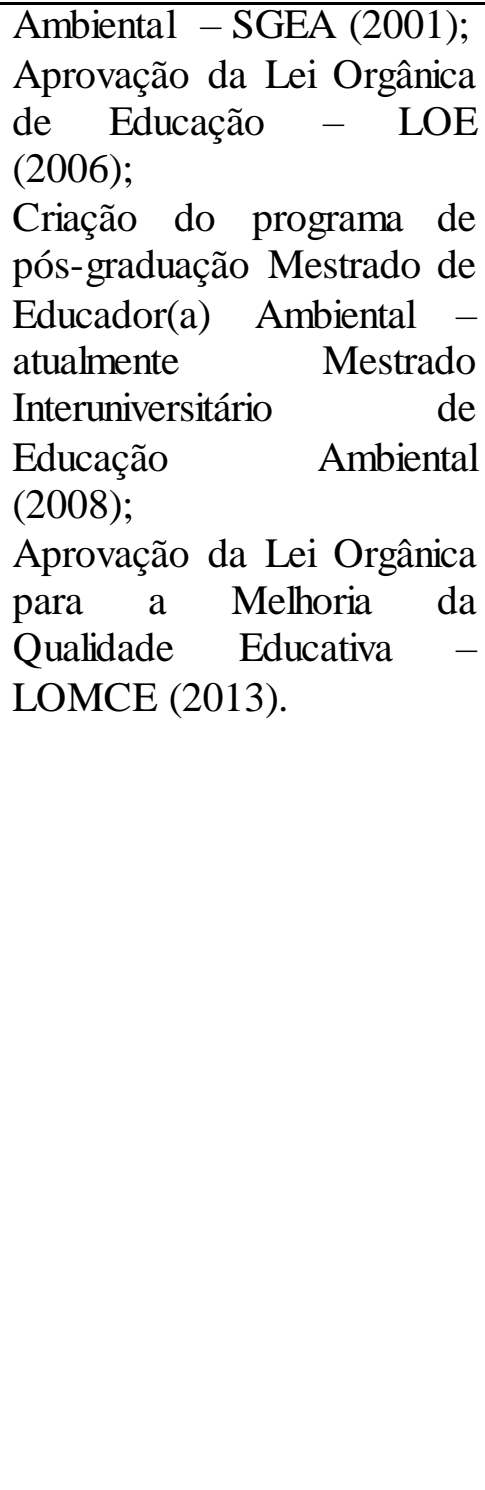 \\
\hline $\begin{array}{l}\text { Concepção abordada nos } \\
\text { documentos }\end{array}$ & $\begin{array}{l}\text { Transversalidade; } \\
\text { Interdisciplinaridade; } \\
\text { Totalidade. }\end{array}$ & $\begin{array}{l}\text { Transversalidade; } \\
\text { Interdisciplinaridade; } \\
\text { Preservação do meio } \\
\text { ambiente. }\end{array}$ \\
\hline Desafios & $\begin{array}{l}\text { Fortalecimento da luta e a } \\
\text { priorização da Educação } \\
\text { Ambiental como pauta dos } \\
\text { Movimentos Sociais, pois } \\
\text { se avalia que as } \\
\text { possibilidades de trabalhar } \\
\text { este tema juntamente com } \\
\text { o Estado, estão sendo } \\
\text { extintas, a exemplo das } \\
\text { reestruturações } \\
\text { apresentadas pelo atual } \\
\text { Governo Federal. }\end{array}$ & $\begin{array}{l}\text { Participação e diálogo dos } \\
\text { Movimentos Sociais com } \\
\text { as Instituições de Ensino } \\
\text { Superior. }\end{array}$ \\
\hline Situação atual & $\begin{array}{llll}\text { Extinção } & \text { dos } & \text { setores } & \text { de } \\
\text { Educação } & \text { Ambiental } & \text { dos } \\
\text { Ministérios } & \text { da } & \text { Educação } & \text { e }\end{array}$ & $\begin{array}{l}\text { Processo de construção } \\
\text { para colocar em prática o } \\
\text { trabalho com a temática, }\end{array}$ \\
\hline
\end{tabular}

Rev. Eletrônica Mestr. Educ. Ambient. Rio Grande, v. 36, n. 3, p. 212-234, set./dez. 2019. E-ISSN 1517-1256 


\begin{tabular}{|c|c|c|c|}
\hline & & $\begin{array}{l}\text { Meio Ambiente, que } \\
\text { constituíam o órgão gestor } \\
\text { da PNEA; } \\
\text { Organização da sociedade } \\
\text { civil para manter o trabalho } \\
\text { e a discussão sobre a } \\
\text { importância desta temática. }\end{array}$ & $\begin{array}{l}\begin{array}{l}\text { conforme dispõem } \\
\text { documentos. }\end{array} \\
\text { os }\end{array}$ \\
\hline
\end{tabular}

Alicerçadas na concepção acima exemplificada, e movidas pelos desafios apresentados - permeadas pelos sentimentos de preocupação e comprometimento -, que se apresenta a seguir, a perspectiva de Educação Ambiental que permeia a discussão deste artigo.

\section{AFINAL, A PARTIR DE QUE PERSPECTIVA COMPREENDEMOS A EDUCAÇÃO AMBIENTAL?}

Para dialogar sobre a perspectiva de Educação Ambiental em que este artigo está embasado, entende-se importante, trazer alguns questionamentos. As grandes empresas divulgam incessantemente, que a Educação Ambiental está presente nos seus projetos, sendo que, em muitos casos, o que desenvolvem são ações pontuais relacionadas ao meio ambiente, com visões lineares e reducionistas sobre a questão ambiental, como condicionante para a aprovação e liberação do empreendimento, geralmente objetivando somente o benefício próprio e desconsiderando a totalidade.

Tais ações, pautadas pela perspectiva conservacionista e naturalista ${ }^{5}$, mostram-se insignificantes ao se considerar o modelo globalizante em que as mesmas estão inseridas e nos danos causados aos trabalhadores, ao meio ambiente e à sociedade. Porém, sabe-se que não é apenas o conceito da expressão "Educação Ambiental" que é diferentemente concebido por essa parcela da população. A discussão vai muito além disso, ou seja, são os alicerces da sociedade capitalista que condicionam a escolha por essa concepção, pois é viável para manter o status quo do sistema. Tonet problematiza que:

[...] é na sociabilidade capitalista que o estranhamento ganha a sua forma mais acabada, pois ali o conjunto do processo, incluindo o produtor, o processo de trabalho e o próprio produto, se torna uma realidade estranha, poderosa e hostil, que se opõe a uma construção autenticamente humana

\footnotetext{
${ }^{5}$ Esta perspectiva é centrada na relação com a natureza. O enfoque educativo pode ser cognitivo (aprender com coisas sobre a natureza), experiencial (ver na natureza e aprender com ela), afetivo, espiritual ou artístico (associando a criatividade humana à da natureza) (SAUVÉ, 2005).
}

Rev. Eletrônica Mestr. Educ. Ambient. Rio Grande, v. 36, n. 3, p. 212-234, set./dez. 2019.

E-ISSN 1517-1256 
dos indivíduos. Deste modo, a construção de uma forma de sociabilidade que abra, para todos a possibilidade de uma vida cheia de sentido, implica, necessariamente, como horizonte, a superação do capital (TONET, 2012, p. 21).

Em diálogo com Tonet, compreende-se que a Educação Ambiental Crítica e Transformadora é um campo de saber que potencializa enquanto devir, o rompimento da lógica capitalista. Sauvé (2005) salienta que esta perspectiva é embasada pela análise das dinâmicas sociais e pelas problemáticas ambientais, assumindo uma postura crítica permeada pelo componente político e apontando para a transformação social. Sauvé (2005, p. 31) afirma que não se trata de uma crítica estéril: "Trata-se de uma postura corajosa, porque ela começa primeiro por confrontar a si mesma ([...] a coerência de seu próprio atuar) e porque ela implica o questionamento [...] das correntes dominantes." Desta forma, entende-se que não são ações isoladas ou atos individuais que farão com que a Educação Ambiental seja trabalhada, de forma a promover a emancipação social. Loureiro contribui com essa discussão, alertando que:

O processo emancipatório almeja, portanto, a construção de uma nova sociedade e organização social na qual os limites que se objetivam na política, na educação, nas instituições e nas relações econômicas possam ser superados democraticamente. Processo que visa garantir aos diferentes agentes sociais efetivas condições de participar e decidir, sob relações de produção que permitam a justa distribuição do que é socialmente criado (alimentos, remédios, roupas, utensilios para proteção, educação, arte, ciência, etc) para que nossa espécie alcance novos modos de viver e se realizar na natureza e não "contra a natureza" (LOUREIRO, 2007, p. 160).

Assim, se faz necessária uma mudança no sistema que, além da Educação Ambiental, usa muitas outras ferramentas que ganham corpo nas discussões a favor da manutenção do seu status quo. Sobre isso, Loureiro enfatiza:

Não cabe mais em Educação Ambiental descontextualizar os temas e se acreditar ingenuamente que é possível reverter esse quadro apenas com a diminuição per capita do consumo ou com mudanças de hábitos familiares e comunitários, colocando a responsabilidade no indivíduo e eximindo de responsabilidade a estrutura social e o modo de produção (LOUREIRO, 2012, p. 61).

Sabe-se que as ferramentas e estratégias utilizadas historicamente, na sociedade, priorizaram o econômico em detrimento ao ambiental, social, cultural. As práticas econômicas da sociedade globalizada como, por exemplo, os usos abusivos dos recursos naturais não renováveis têm ameaçado bruscamente o meio ambiente. É necessário um Rev. Eletrônica Mestr. Educ. Ambient. Rio Grande, v. 36, n. 3, p. 212-234, set./dez. 2019. 
enfrentamento no sentido de romper com estas práticas, conforme ressalta Tse-Tung (2009, p. 34): "A filosofia marxista sustenta que a questão mais importante não é compreender as leis do mundo objetivo e poder, por isso, explicá-lo, mas sim utilizar o conhecimento dessas leis para transformar ativamente o mundo." Nesse sentido, Marx elucida que, através do trabalho, as pessoas se relacionam com a natureza não humanizada, transformando-a:

Antes de tudo, o trabalho é um processo de que participam o homem e a natureza, processo em que o ser humano com sua própria ação impulsiona, regula e controla seu intercâmbio material com a natureza. Defronta-se com a natureza como uma de suas forças. Põe em movimento as forças naturais de seu corpo, braços e pernas, cabeça e mãos, a fim de apropriar-se dos recursos da natureza, imprimindo-lhes forma útil à vida humana. Atuando assim sobre a natureza externa e modificando-a, ao mesmo tempo modifica sua própria natureza. Desenvolve as potencialidades nela adormecidas e submete ao seu domínio o jogo das forças naturais (MARX, 2004, p. 36).

Sendo assim, o homem transforma a natureza a partir das suas necessidades, sendo esta relação condicionada pelo sistema vigente e, consequentemente, pelo modo de produção. Por isso, entende-se que a Educação Ambiental tem um papel importante no sentido de discutir e repensar um novo paradigma de desenvolvimento, que para Mészáros:

Mudar essas condições exige uma intervenção consciente em todos os domínios e em todos os níveis da nossa existência individual e social. É por isso que, segundo Marx, os seres humanos devem mudar 'completamente as condições da sua existência industrial e política, e, consequentemente, toda a sua maneira de ser' (MÉSZÁROS, 2008, p. 59 , grifo do autor).

Tendo em vista a reflexão acima, bem como a realidade da sociedade, torna-se cada vez mais evidente a importância da Educação Ambiental Crítica e Transformadora, cuja complexidade requer um trabalho comprometido, baseado na práxis, que considere as diversas dimensões como: social, política, econômica, ética, estética, pedagógica e cultural. Neste sentido, propor uma Educação Ambiental alicerçada na práxis significa trabalhar com o conflito, com a contradição, com a realidade, agindo para transformar, pois segundo Loureiro (2012), a práxis é considerada como atividade transformadora, que trabalha a partir da realidade cotidiana, visando à superação das relações de dominação.

\section{FINALIZAR EM TEMPOS DE ENFRENTAMENTOS}

Rev. Eletrônica Mestr. Educ. Ambient. Rio Grande, v. 36, n. 3, p. 212-234, set./dez. 2019. E-ISSN 1517-1256 
A partir da discussão da Educação Ambiental, tanto no Brasil quanto na Espanha, compreende-se que aquela é importante por contribuir para promover a reestruturação política e econômica da sociedade, na perspectiva de fortalecer os diversos segmentos e atores sociais (comprometidos com outro modelo de sociedade), para a superação do sistema que está posto. A Educação Ambiental em que se aposta tem, como objetivo, a formação de sujeitos situados e críticos, identificados com sua realidade e construindo conhecimentos a partir da reflexão sobre suas práticas em relação aos conhecimentos socialmente produzidos, tendo relação permanente e coerente entre teoria e prática, ou seja, a práxis.

Verificou-se também, que, nos dois países, a conjuntura política influencia consideravelmente, tanto de maneira significativa, quanto de maneira negativa nos espaços institucionais, nas discussões e nas ações em relação à Educação Ambiental. Assim, governantes oriundos das classes populares e com uma perspectiva política alicerçada nas bases de esquerda demonstram-se mais acessíveis e comprometidos com a temática, por seus projetos políticos estarem fundamentados na perspectiva contra hegemônica. Já, governantes apoiados em uma linha política de direita, tendem a manter e fortalecer o projeto hegemônico de sociedade, priorizando os desejos da minoria às necessidades da maioria.

Assim sendo, reafirma-se que não existe neutralidade em discursos e ações, estando esses revestidos ou mascarados por ideologias políticas. Portanto, no cenário político atual, mais do que nunca, torna-se importante o fortalecimento, a luta e a priorização da Educação Ambiental como pauta dos Movimentos Sociais, pois se avalia que as possibilidades de trabalhar juntamente com o Estado passam por um processo de transformação, em que o cenário se evidencia desfavorável para a questão ambiental, na perspectiva crítica e transformadora.

\section{REFERÊNCIAS}

BENAYAS, Javier; GUTIÉRREZ, José; HERNANDÉZ, Norma. La investigación en Educación Ambiental en España. ISBN: 84-8014-513-7, NIPO: 311-03-041-8, Depósito legal: M. 43320-2003. Madrid: Ministerio de Medio Ambiente, Secretaría, General de Medio Ambiente, Organismo Autónomo Parques Nacionales, 2003.

BRASIL. Ministério do Meio Ambiente. Diretoria de Educação Ambiental; Ministério da Educação-Coordenação Geral de Educação Ambiental. Programa Nacional de Educação Ambiental - ProNEA. 3. ed. Brasilia: Ministério do Meio Ambiente, 2005. 
BRASIL. Constituição Federal (1988). Constituição da República Federativa do Brasil: texto promulgado em 05 de outubro de 1988. Brasília: Senado Federal, 2013.

CARTEA, Pablo Ángel Meira; SANTIAGO, Miguel Padellas. Proxecto fénix: investigando y actuando en La educación ambiental gallega. Galícia: Centro Nacional de Educación Ambiental, 2010.

DUARTE, Wander de Jesus Barboza. Um paralelo sobre a Educação Ambiental no Brasil e na Espanha. Revista Educação Ambiental em ação, Novo Hamburgo, ISSN 1678-0701, ano XVII, n, 64, jun.-ago. 2018. Disponível em:

<http://www.revistaea.org/artigos.php?idsecao=1>. Acesso em: 19 fev. 2019.

ESTEBAN IBAÑEZ, Macarena. Educación Ambiental. Evolución y desarrollo en el contexto reglado escolar español. Revista Científica RUNAE, Sevilla-España, ISSN 25506854, v. 1, n. 1, m. 1, 2017, p. 221-240. Disponível em: <http://runae.unae.edu.ec/revistas3/index.php/RUNAE/article/view/50>. Acesso em: 18 fev. 2019.

FERNÁNDEZ, Javier García; ORTEGA, Yolanda Sampedro. Un viaje por la educación ambiental en España: Una visita a algunas de las iniciativas: promovidas desde la administración general y autonómica tras la publicación del Libro Blanco. ISBN-10: 848014-673-7, ISBN-13: 978-84-8014-673-7, NIPO:311-06-037-2, Depósito Legal: M.40.292-2006. Madrid: Ministerio de Medio Ambiente - Organismo Autónomo Parques Nacionales, 2006.

LOUREIRO, Carlos Frederico Bernardo (Org.) [et al.]. A questão ambiental no pensamento crítico: natureza, trabalho e educação. Rio de janeiro: Quartet, 2007.

LOUREIRO, Carlos Frederico Bernardo. Trajetória e fundamentos da Educação Ambiental. 4. ed. São Paulo: Cortez, 2012.

MARX, Karl. Processo de trabalho e processo de valorização. In: ANTUNES, Ricardo (org.). A dialética do Trabalho. São Paulo: Expressão Popular, 2004.

MAYER, Michaela. Educación Ambiental: de la acción a la investigación. Enseñanza de lãs Ciências. Roma, Itália, v.16, n.2, 1998, p. 217-231. Disponível em: <https://www.raco.cat/index.php/Ensenanza/article/.../21364>. Acesso em: 13 fev. 2019.

MÉSZÁROS, Isteván. A educação para além do capital. 2. ed. São Paulo: Boitempo, 2008.

SALORT, Michelle Coelho. O entrelaçamento entre o Ensino de Arte e a Educação Ambiental: para construir, compartilhar, pertencer. 2016. 304 f. Tese (Doutorado em Educação Ambiental) - Programa de Pós-Graduação em Educação Ambiental, Universidade Federal do Rio Grande, Rio Grande, 2016.

SAUVÉ, Lucie. Uma cartografia das correntes em Educação Ambiental. In: SATO, Michèle; CARVALHO, Isabel Cristina Moura (Orgs.). Educação ambiental: pesquisa e desafio. Porto Alegre: Artmed, 2005. 
TONET, Ivo. Educação contra o capital. 2. ed. São Paulo: Instituto Lukács, 2012.

TSE-TUNG, Mao. Sobre a prática - sobre a contradição. 1. ed. São Paulo: Expressão Popular, 2009.

UNIVERSIDADE PABLO DE OLAVIDE - UPO. Máster Educación Ambiental.

Disponível em: <http://www.upo.es/postgrado/Master-Oficial-Educacion-Ambiental>. Acesso em: 25 jan. 2019.

Submetido em: 15-10-2019

Publicado em: 17-12-2019 